\title{
ATP-dependent potassium channels contribute to motor regulation of esophageal striated muscle in rats
}

\author{
Kazuhiro HORII)\#, Yuji SUZUKI 1)\#, Takahiko SHIINA ${ }^{1) *}$, Shouichiro SAITO2), \\ Sawa ONOUCHI'), Yuuki HORII ${ }^{1)}$, Hiroki SHIMAOKA ${ }^{1)}$ and Yasutake SHIMIZU ${ }^{1,3)}$ \\ ${ }^{1)}$ Department of Basic Veterinary Science, Laboratory of Physiology, The United Graduate School of Veterinary \\ Sciences, Gifu University, 1-1 Yanagaido, Gifu 501-1193, Japan \\ 2) Department of Basic Veterinary Science, Laboratory of Anatomy, The United Graduate School of Veterinary \\ Sciences, Gifu University, 1-1 Yanagaido, Gifu 501-1193, Japan \\ 3) Center for Highly Advanced Integration of Nano and Life Sciences (G-CHAIN), Gifu University, 1-1 Yanagaido, \\ Gifu 501-1193, Japan
}

J. Vet. Med. Sci.

81(9): 1266-1272, 2019

doi: 10.1292/jvms.19-0197

Received: 11 April 2019

Accepted: 27 June 2019

Advanced Epub: 9 July 2019

\begin{abstract}
The aim of the present study was to clarify roles of ATP-dependent potassium channels ( $\mathrm{K}_{\text {ATP }}$ channels) in motility of the striated muscle portion in the esophagus. An isolated segment of the rat esophagus was placed in an organ bath and mechanical responses were recorded using a force transducer. Electrical stimulation of the vagus nerve evoked contractile response of striated muscle in the esophageal segment. Application of glibenclamide, an antagonist of $\mathrm{K}_{\text {ATP }}$ channels, increased amplitude of vagally mediated twitch contractions of the rat esophagus. On the other hand, minoxidil, an agonist of $\mathrm{K}_{\text {ATP }}$ channels, decreased amplitude of twitch contractions. RT-PCR revealed the expression of subunits of $\mathrm{K}_{\text {ATP }}$ channels in esophageal tissue. In addition, immunopositivity for subunits of $\mathrm{K}_{\mathrm{ATP}}$ channels was observed in the striated muscle cells of the esophageal muscle layer. These findings indicate that $\mathrm{K}_{\text {ATP }}$ channels contribute to motor regulation of striated muscle in the rat esophagus.
\end{abstract}

KEY WORDS: ATP-dependent potassium channel, esophagus, rat, striated muscle

The external muscle layer of the mammalian esophagus contains not only smooth muscle fibers but also striated muscle fibers, in contrast to other gastrointestinal tracts such as the stomach, small intestine and large intestine [23, 37]. The distributions of striated and smooth muscles are known to vary extremely among animal species $[1,29]$. In dogs, ruminants and rodents including mice, rats and hamsters, the muscle layer of esophagus consists largely of striated muscle fibers. In humans and cats, the upper and lower portions of esophagus are composed of striated and smooth muscle fibers, respectively, with mixed composition of these fibers in the middle portion. In contrast, in the chicken and quail esophagi, whole length consists of smooth muscle fibers alone, as like other gastrointestinal tracts. Motility of the striated muscle portion in the esophagus is regulated by the vagus nerve [9, 13]. In addition to extrinsic vagal neuronal regulation, a local neural pathway involving capsaicin-sensitive sensory neurons and intrinsic nitrergic neurons controls motility of esophageal striated muscle [8, 16, 26, 28]. Capsaicin-activated primary afferent neurons act on myenteric nitrergic neurons, which release nitric oxide (NO), and then NO can inhibit the release of acetylcholine from vagal motor neurons in the striated muscle esophagus $[8,16,26,28]$.

ATP-dependent potassium channels ( $\mathrm{K}_{\text {ATP }}$ channels), which are inhibited by cytosolic ATP, are composed of inward-rectifying potassium channel subunits (Kir6.1 and Kir6.2) and regulatory sulfonylurea receptors (SUR1, SUR2A and SUR2B) [2, 4, 15, 25]. $\mathrm{K}_{\text {ATP }}$ channels are expressed in several tissues including the heart, brain, blood vessel and gastrointestinal smooth muscles, skeletal muscle, and pancreatic $\beta$ cells $[3,10,22,24,31,32,34,35]$. The esophageal smooth muscle also has $\mathrm{K}_{\text {ATP }}$ channels [35]. Hatakeyama et al. reported that agonists of $\mathrm{K}_{\mathrm{ATP}}$ channels generate outward currents in smooth muscle cells of the muscularis mucosa of the rabbit esophagus [14]. In addition, nicorandil, an agonist of $\mathrm{K}_{\mathrm{ATP}}$ channels, causes relaxation of smooth muscle in the lower esophageal sphincter (LES) of the rat [30].

On the other hand, it is unclear whether $\mathrm{K}_{\text {ATP }}$ channels are involved in the regulation of striated muscle motility in the esophagus. Therefore, the aim of the present study was to clarify roles of $\mathrm{K}_{\mathrm{ATP}}$ channels in motility of the esophageal striated muscle in the rat. 


\section{MATERIALS AND METHODS}

\section{Animals}

Male Sprague-Dawley rats (Rattus norvegicus, 9-11 weeks of age, 300-350 g in weight) were obtained from Japan SLC (Shizuoka, Japan). They were maintained in plastic cages at $24 \pm 2{ }^{\circ} \mathrm{C}$ with a 12:12-hr light-dark cycle (light on at 07:00-19:00) and given free access to laboratory chow and water. The experiments were approved by the Gifu University Animal Care and Use Committee and were conducted in accordance with the committee guidelines on animal care and use (permission numbers: 14105, 15098 and 17005).

\section{Esophageal tissue preparations}

Animals were anesthetized with isoflurane and were exsanguinated via axillary arteries. A 1-cm-long segment from the middle thoracic part of the esophagus was dissected out. The segment of the esophagus was immediately immersed in Krebs' solution (see below) at room temperature, and the intraluminal contents of the excised segment were flushed using a small cannula containing Krebs' solution.

\section{Recording of mechanical activity in esophageal segments}

The whole segment was transferred to a $10-\mathrm{m} l$ thermostatically controlled $\left(35^{\circ} \mathrm{C}\right)$ organ bath containing Krebs' solution bubbled with $95 \% \mathrm{O}_{2}+5 \% \mathrm{CO}_{2}$ gas mixture and maintained at $\mathrm{pH}$ 7.4. Contractile activity was measured in the circular direction so as to avoid contamination from contractions of the longitudinally oriented smooth muscularis mucosae. Two L-shaped stainless-steel pins were introduced into the esophageal lumen; one pin was fixed to the bottom of the organ bath and the other was connected to the bar of an isometric force transducer (T7-8-240; Orientec, Tokyo, Japan). Contractile responses were recorded isometrically on the PowerLab system (AD Instruments, Bella Vista, NSW, Australia) through an AC amplifier (AS1202, NEC, Tokyo, Japan) (Fig. 1). An initial resting tension of $1.0 \mathrm{~g}$ was applied to the preparations, which were subsequently allowed to equilibrate for at least 30 $\min$.

\section{Electrical stimulations}

Electrical stimulations were applied to esophageal preparations for inducing muscle contractile response. In experiments using vagal stimulation, the end of the vagus nerve trunk was drawn into a bipolar suction electrode and the electrode was immersed together with the esophagus preparation in the bath (Fig. 1). For avoiding interference with tissue movement, the electrode was fixed loosely. The vagus nerve was stimulated using an electronic stimulator (model SEN-3201, Nihon Kohden, Tokyo, Japan) connected to the electrodes. For stimulation of vagus nerves to evoke twitch contractions, single square-wave pulses of supramaximal intensity $(80 \mathrm{~V})$ and $100 \mu \mathrm{sec}$ in duration were applied at intervals of $1 \mathrm{~min}$.

\section{Solutions and drugs}

During experiments, tissues were maintained in Krebs' solution consisting of (mM): $\mathrm{NaCl} 118.4, \mathrm{KCl} 4.7, \mathrm{CaCl}_{2} 2.5, \mathrm{MgSO}_{4}$ 1.2, $\mathrm{KH}_{2} \mathrm{PO}_{4} 1.2, \mathrm{NaHCO}_{3} 25$ and glucose 11.7. D-tubocurarine was obtained from Sigma-Aldrich (St. Louis, MO, U.S.A.). Glibenclamide and minoxidil were obtained from Tokyo Chemical Industry (Tokyo, Japan). D-tubocurarine was dissolved in distilled water. Glibenclamide and minoxidil were dissolved in DMSO. The highest concentration of vehicles (1\%) for the drugs alone had no effect on the basal tone and contractile responses. The concentrations of drugs given were final concentrations in the bath solution. Glibenclamide and minoxidil were applied accumulatively.

\section{$R N A$ isolation and reverse transcription-polymerase chain reaction (RT-PCR)}

The expression of $\mathrm{K}_{\mathrm{ATP}}$ channel gene mRNA was assessed by RT-PCR. Total cellular RNA was extracted from tissue

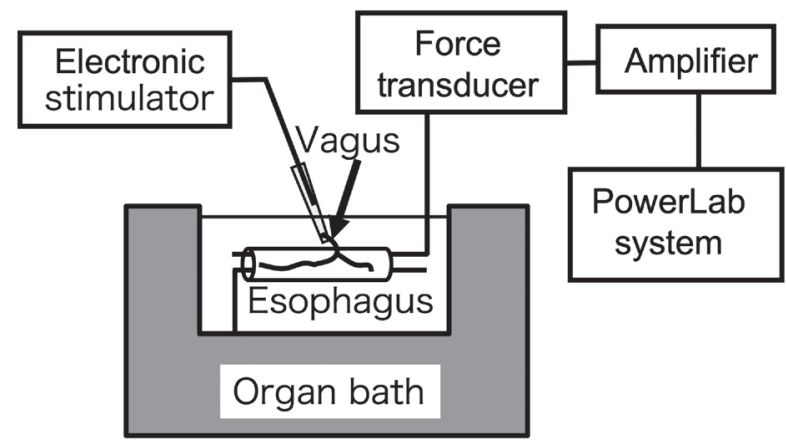

Fig. 1. Experimental apparatus for recording of mechanical activity in an esophageal segment. The whole segment was immersed in an organ bath containing Krebs' solution $\left(35^{\circ} \mathrm{C}\right)$ bubbled with $95 \% \mathrm{O}_{2}+5 \% \mathrm{CO}_{2}$ gas mixture and maintained at $\mathrm{pH} 7.4$. Contractile responses were recorded isometrically in the circular direction. Electrical stimulations were applied to the vagus nerve trunk for inducing muscle contractile response. 
homogenates of the rat esophagus using TRI Reagent (Molecular Research Center, Cincinnati, OH, U.S.A.). First-strand cDNA was synthesized from $2 \mu \mathrm{g}$ of total RNA by using SuperScript III Reverse Transcriptase (Thermo Fisher Scientific) and Random primers (Thermo Fisher Scientific). The absence of PCR-amplified DNA fragments in the samples without reverse transcription indicated the isolation of RNA free from genomic DNA contamination. PCR was performed with Platinum Taq DNA Polymerase High Fidelity (Thermo Fisher Scientific). The primer sets were as follows: Kir6.1 sense 5'AAAGGAAGATGCTGGCCAGGAA -3' and anti-sense 5'- CCGTGATGCCTTTCTCCATGTA -3' (predicted size=339 bp), Kir6.2 sense 5'- CGCATGGTGACAGAGGAATG -3' and anti-sense 5'- GTGGAGAGGCACAACTTCGC -3' (predicted size=297 bp), SUR1 sense 5'- TGGGGAACGGGGCATCAACT -3' and anti-sense 5'- TGGCTCTGGGGCTTTTCTC -3' (predicted size $=388$ bp), SUR2A sense 5'- TTGTTCGAAAGAGCAGCATAC -3' and anti-sense 5'- GCCCGCATCCATAATAGAGG -3' (predicted

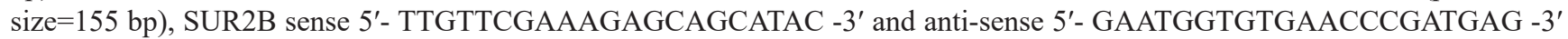
(predicted size $=144 \mathrm{bp}$ ). All primers were purchased from Thermo Fisher Scientific. Amplifications were performed by 35 cycles. The reaction products were electrophoresed on $1.5 \%$ agarose gels and stained with ethidium bromide $(0.8 \mu \mathrm{g} / \mathrm{m} l)$. The gels were imaged with the ChemiDoc ${ }^{\mathrm{TM}}$ XRS+ system (BIO RAD, Hercules, CA, U.S.A.) and photographed.

\section{Section preparation}

Rats were anesthetized with pentobarbital sodium (50 mg/kg i.p.) and transcardially perfused with Ringer's solution (200 ml) followed by $4 \%$ paraformaldehyde in $0.1 \mathrm{M}$ phosphate buffer $(\mathrm{pH} 7.4 ; 200 \mathrm{~m} l)$. The esophagi were isolated and post fixed at $4{ }^{\circ} \mathrm{C}$ overnight. Each middle esophagus was divided into two parts for cryostat sections and paraffin sections.

For cryostat sections, the specimens were rinsed in phosphate buffered saline (PBS; pH 7.4) and stored in $30 \%$ sucrose in PBS at $4^{\circ} \mathrm{C}$ overnight. They were then frozen with OCT compound medium (Sakura Finetech Japan, Tokyo, Japan). Cryostat sections were transversely cut at $15 \mu \mathrm{m}$ in thickness, mounted on slides coated with poly-1-lysine.

For paraffin sections, the specimens were gradually dehydrated by ethanol from $70 \%$ to $100 \%$ before treated by xylene. Then, the specimens were embedded in paraffin and transversely cut at $5 \mu \mathrm{m}$ in thickness. Before immunohistochemistry, the sections were deparaffined and heated in $10 \mathrm{mM}$ citrate buffer at $105^{\circ} \mathrm{C}$ for $20 \mathrm{~min}$ to perform antigen retrieval.

\section{Immunohistochemistry}

The sections were immersed in $0.3 \% \mathrm{H}_{2} \mathrm{O}_{2}$ in methanol at room temperature for $20 \mathrm{~min}$ to eliminate endogenous peroxidase, followed by rinsing in PBS. The sections were then incubated with $2 \%$ normal goat serum at room temperature for 30 min. After rinsing in PBS, the sections were incubated with anti-SUR1 polyclonal antibody (catalog number: bs-3641R; lot number: 9B21M9; Bioss, Boston, MA, U.S.A.) diluted 1:100 or with anti-Kir6.1 polyclonal antibody (catalog number: bs-6468R; lot number: AF02227906; Bioss) diluted 1:100 at $4^{\circ} \mathrm{C}$ overnight. After rinsing in PBS, the sections were incubated with biotinylated goat anti-rabbit IgG (Chemicon, Temecula, CA, U.S.A.) diluted 1:500 at room temperature for $30 \mathrm{~min}$. After rinsing in PBS, the sections were incubated with Vectastain $\mathrm{ABC}$ reagent (Vector, Burlingame, CA, U.S.A.) at room temperature for 30 min. Finally, the sections were colorized for $10 \mathrm{~min}$ in $0.1 \mathrm{M}$ Tris-HCl, $\mathrm{pH} 7.4$, containing $0.02 \%$ DAB and $0.003 \% \mathrm{H}_{2} \mathrm{O}_{2}$, then counterstained with hematoxylin, dehydrated and cover slipped. Negative controls were created using normal rabbit IgG (FUJIFILM Wako Pure Chemical Corp., Osaka, Japan) to replace the primary antibody. No specific staining was observed in the control sections.

\section{Statistical analysis}

Data are presented as means \pm standard deviation (S.D.) or means \pm standard error of the mean (S.E.M.). $n$ indicates the number of separate preparations. The significance of differences between mean values was determined by one-way repeated measures analysis of variance followed by Sidak's test for multiple comparisons. A $P$ value less than 0.05 denotes the presence of a statistically significant difference.

\section{RESULTS}

\section{Contractile responses of rat esophageal segments induced by electrical stimulation}

In the absence of stimulation, no spontaneous responses occurred in the rat esophagus. Electrical stimulation of the vagus nerve trunk with single pulses evoked monophasic (twitch-like) contractile responses in the rat esophagus (Fig. 2). Amplitude of the contractile response was 0.77 $\pm 0.56 \mathrm{~g}$ (mean \pm S.D.; $n=11$ ). The responses were stable in magnitude for more than $1 \mathrm{hr}$. The contractile responses were abolished by treatment with d-tubocurarine $(5 \mu \mathrm{M})$, a blocker of nicotinic acetylcholine receptors (Fig. 2).

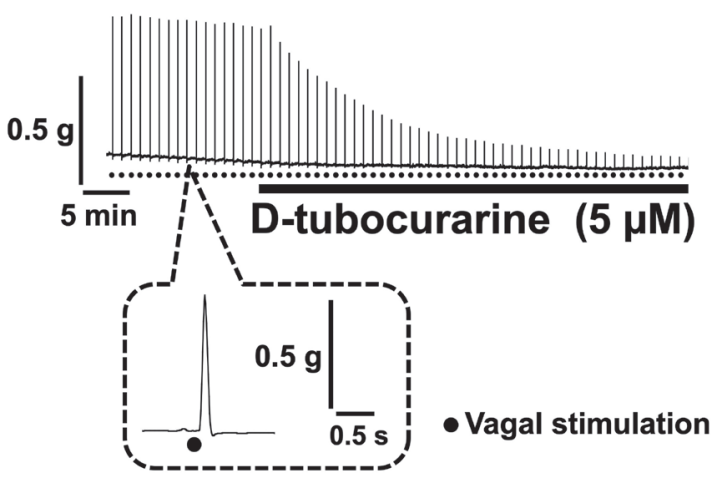

Fig. 2. Contractile responses elicited by electrical stimulation of the vagus nerve in the rat esophagus. A representative tracing of vagally mediated contractions in the rat esophagus is shown. Electrical stimulations were applied to the vagus using single pulses at 80 $\mathrm{V}, 100-\mu \mathrm{sec}$ pulse duration, at 1-min intervals, and circular mechanical responses were recorded isometrically. Electrical stimulation of the vagus trunk induced monophasic contractions of esophageal striated muscle. D-tubocurarine was added to the organ bath at a final concentration of $5 \mu \mathrm{M}$. Dots show the points of singlepulse electrical stimulations. 
Effects of a selective antagonist or agonist of $K_{A T P}$ channels on vagally mediated contractions of the rat esophageal striated muscle

To determine whether $\mathrm{K}_{\mathrm{ATP}}$ channels are involved in the regulation of vagally mediated twitch contractions in the rat esophagus, an antagonist of the channels, glibenclamide, and an agonist of the channels, minoxidil, were used. Application of glibenclamide $(50 \mu \mathrm{M} \sim 1 \mathrm{mM})$ increased dose-dependently vagally mediated twitch contractions of the rat esophagus (Fig. 3). On the other hand, application of minoxidil (10-200 $\mu \mathrm{M}$ ) decreased twitch contractions in a dose-dependent manner (Fig. 4).

\section{Molecular identification of $K_{A T P}$ channels in the rat esophagus}

We then examined the expression of subunits of $\mathrm{K}_{\text {ATP }}$ channels in the rat esophagus by using RT-PCR. Amplified products of mRNA of Kir6.1, Kir6.2, SUR1, SUR2A and SUR 2B, subunits of $\mathrm{K}_{\text {ATP }}$ channels, were observed in appropriate sizes (Fig. 5).

\section{Immunostaining for $K_{A T P}$ channels in the rat esophagus}

To examine distribution of $\mathrm{K}_{\text {ATP }}$ channels in the rat esophageal tissue, we performed immunohistochemistry by using antibodies for subunits of $\mathrm{K}_{\mathrm{ATP}}$ channels. In the paraffin section, the esophagus showed stratified squamous epithelium, discontinuous lamina muscularis, and two muscular layers composed of striated muscle cells (Fig. 6). Kir6.1 immunoreactivity was mainly observed in the striated muscle cells and slightly observed in the lamina muscularis (Fig. 6A). Kir6.1 immunoreactivity in the cryostat section was similar with the paraffin section (Fig. 7A). In addition, in the cryostat section, SUR1 immunoreactivity was also observed in the striated muscle cells of the muscle layer (Fig. 7B).

\section{DISCUSSION}

In this study, we examined roles of $\mathrm{K}_{\text {ATP }}$ channels in motility of the esophageal striated muscle in the rat. We detected expression of subunits of $\mathrm{K}_{\text {АтP }}$ channels in the rat esophageal tissue, especially in the striated muscle cells of the muscle layer, and then tested pharmacological effects of an antagonist and an agonist of $\mathrm{K}_{\text {ATP }}$ channels. We demonstrated that glibenclamide, an antagonist of

A

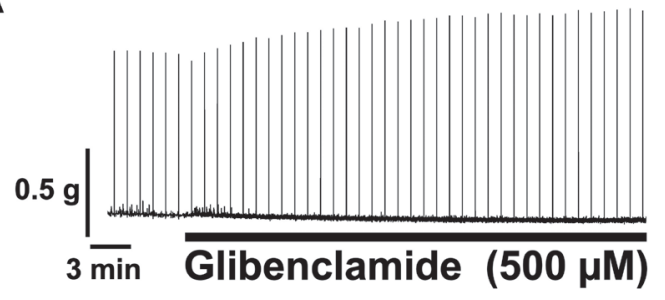

B

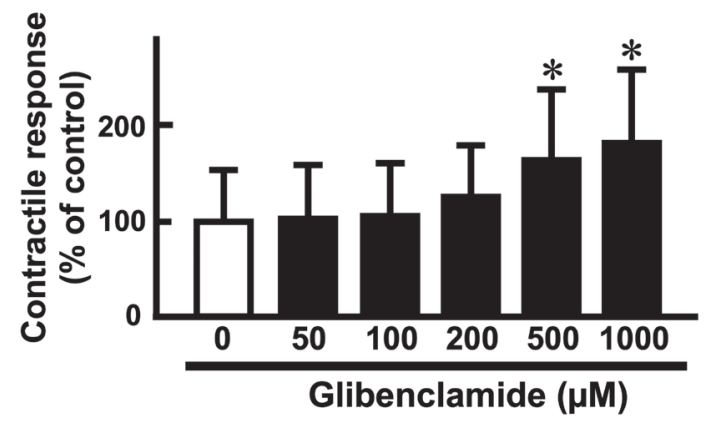

Fig. 3. Effects of a selective antagonist of $\mathrm{K}_{\mathrm{ATP}}$ channels, glibenclamide, on vagally evoked contractions of striated muscle in the rat esophagus. (A) A representative trace showing the effect of glibenclamide $(500 \mu \mathrm{M})$ on vagally mediated twitch contractions. Electrical stimulations were applied to the vagus nerve using single pulses of $80 \mathrm{~V}$ with a $100-\mu \mathrm{sec}$ pulse duration at 1-min intervals, and glibenclamide was added to the organ bath at a final concentration of $500 \mu \mathrm{M}$. (B) Summary graphs of the effect of glibenclamide ( $50 \mu \mathrm{M} \sim 1 \mathrm{mM})$ on contractility in the rat esophageal striated muscle $(n=6)$. Glibenclamide was applied accumulatively. Each bar represents the mean \pm S.E.M. $* P<0.05$, compared to the control, which is the response before application of glibenclamide.

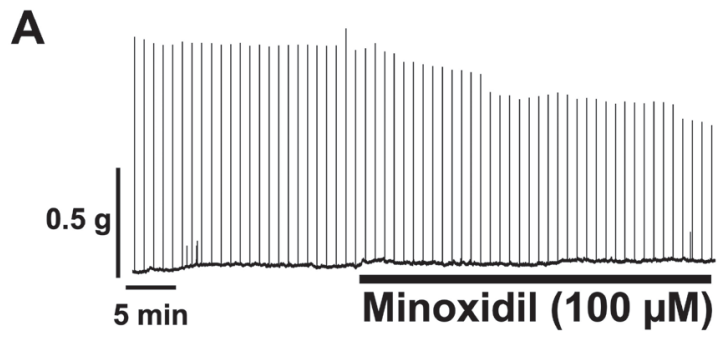

B

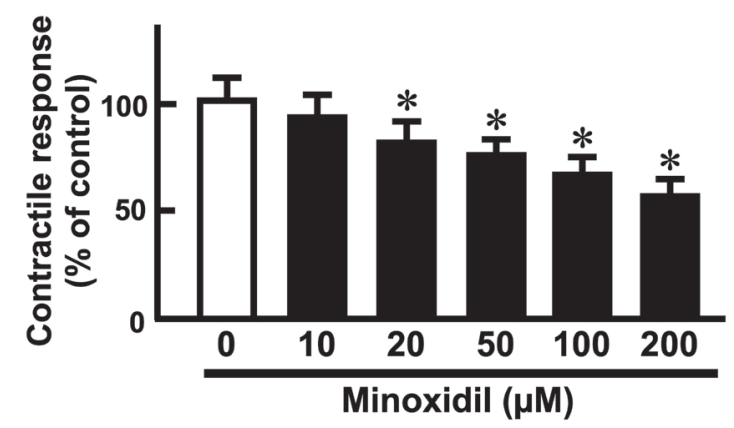

Fig. 4. Effects of a selective agonist of $\mathrm{K}_{\mathrm{ATP}}$ channels, minoxidil, on vagally evoked contractions of striated muscle in the rat esophagus. (A) A representative trace showing the effect of minoxidil (100 $\mu \mathrm{M})$ on vagally mediated twitch contractions. Electrical stimulations were applied to the vagus nerve using single pulses of $80 \mathrm{~V}$ with a $100-\mu$ sec pulse duration at 1 -min intervals, and minoxidil was added to the organ bath at a final concentration of $100 \mu \mathrm{M}$. (B) Summary graphs of the effect of minoxidil (10-200 $\mu \mathrm{M})$ on contractility in the rat esophageal striated muscle $(n=5)$. Minoxidil were applied accumulatively. Each bar represents the mean \pm S.E.M. ${ }^{*} P<0.05$, compared to the control, which is the response before application of minoxidil. 


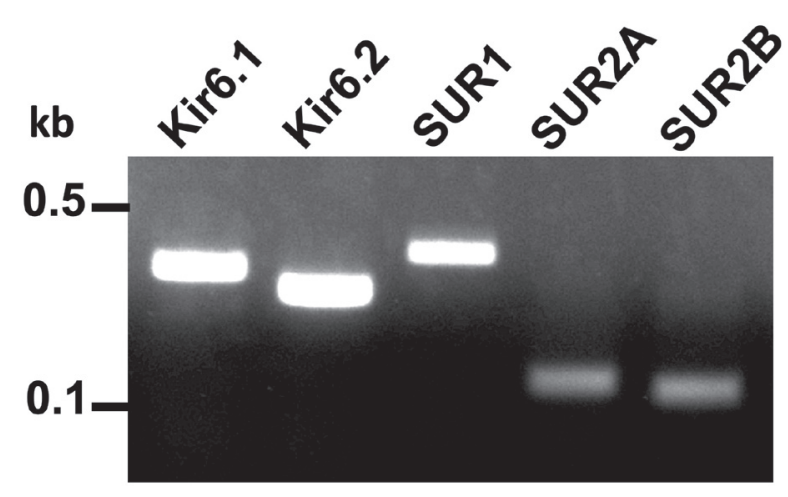

Fig. 5. Expression of subunits of $\mathrm{K}_{\text {ATP }}$ channels in the rat esophagus determined by RT-PCR. Homogenized samples from the rat tissues were used for RT-PCR. Amplified products of mRNA of Kir6.1, Kir6.2, SUR1, SUR2A and SUR2B were detected in appropriate sizes ( $n=3$ ).
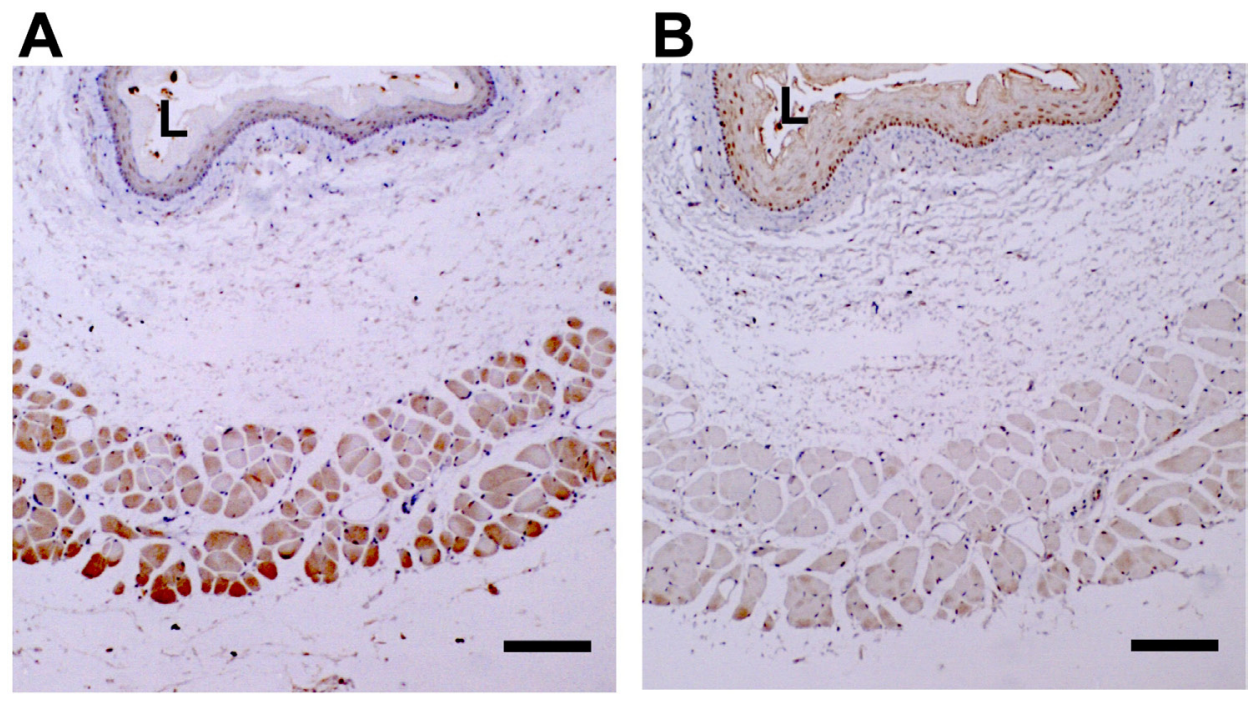

Fig. 6. Histological examinations of the rat esophagus with paraffin section. (A) Kir6.1 immunoreactivity was observed mainly in the muscular layer in the rat esophagus. (B) The control staining using a normal rabbit IgG instead of antibody for $\mathrm{K}_{\text {ATP }}$ channel. No specific staining was observed. L shows the lumen. Scale bar $=100 \mu \mathrm{m}$.

A

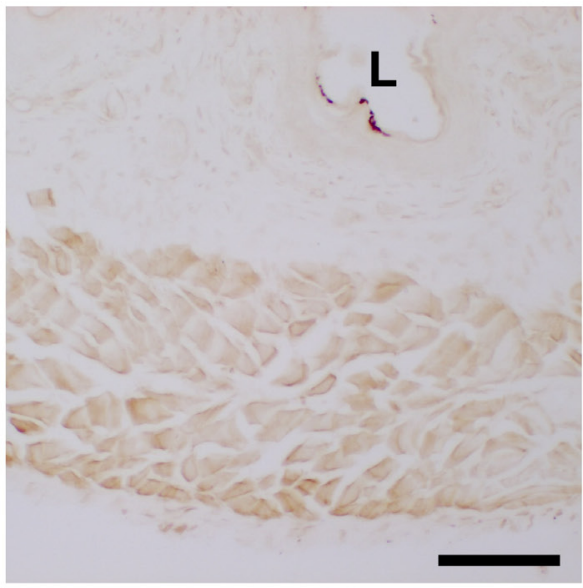

B

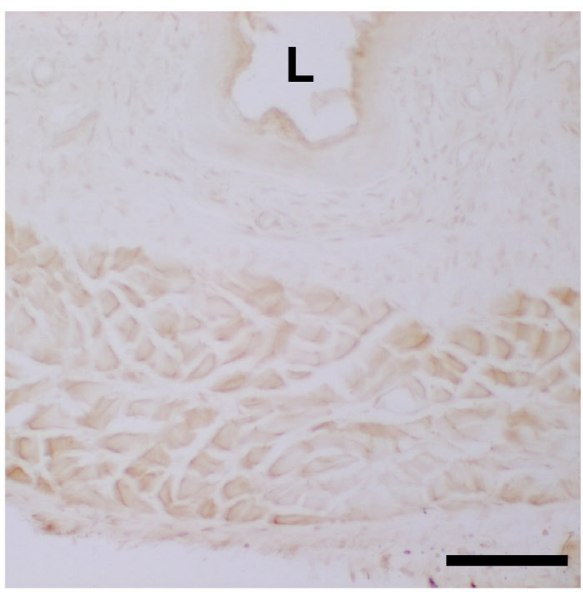

C

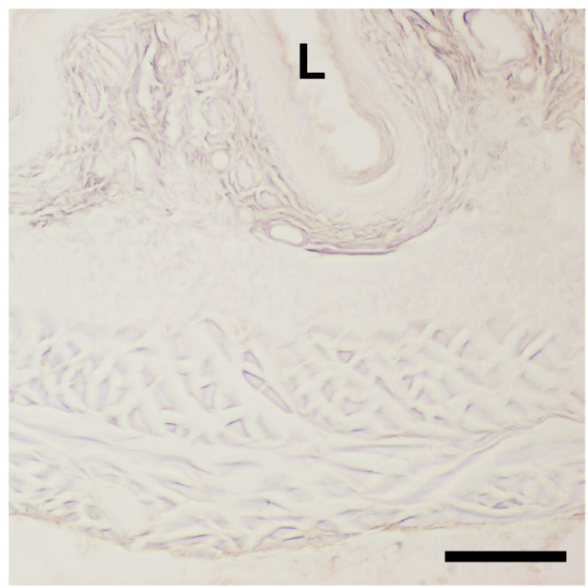

Fig. 7. Histological examinations of the rat esophagus with cryostat section. The muscular layer of the rat esophagus showed immunoreactivity by antibodies not only for Kir6.1 (A) but also for SUR1 (B). (C) The control staining using a normal rabbit IgG instead of antibody for $\mathrm{K}_{\text {ATP }}$ channel. No specific staining was observed. L shows the lumen. Scale bar $=100 \mu \mathrm{m}$. 
$\mathrm{K}_{\mathrm{ATP}}$ channels that can shut the channels, enhances vagal stimulation-induced contraction of esophageal striated muscle. On the other hand, the agonist minoxidil, which can gate $\mathrm{K}_{\mathrm{ATP}}$ channels, blocks esophageal striated muscle contractions. These results suggest that $\mathrm{K}_{\mathrm{ATP}}$ channels may play a role in the regulation of striated muscle motility in the esophagus. In accordance with our study, previous studies have also shown similar effects of antagonists and agonists of $\mathrm{K}_{\mathrm{ATP}}$ channels on smooth muscle motility in other gastrointestinal tracts such as the stomach, ileum and colon [18-20, 33, 38].

Since $\mathrm{K}_{\mathrm{ATP}}$ channels are closed by an increase in intracellular ATP, it is thought that the cellular metabolic state influences the activity of $\mathrm{K}_{\text {ATP }}$ channels $[3,7,11,34]$. In fact, activation of $\mathrm{K}_{\text {ATP }}$ channels, in response to reduction of ATP/ADP ratio, might underlie a decrease in action potential duration and hence twitch force in skeletal muscle with fatigue [34]. These findings indicate the possibility that $\mathrm{K}_{\mathrm{ATP}}$ channels control esophageal striated muscle motility in response to changes in nutritional status. When intracellular ATP is increased by high food intake, $\mathrm{K}_{\mathrm{ATP}}$ channels are closed and then the esophageal striated muscle motility would be activated. This is consistent with the demand for enhancement of esophageal motility induced by food intake.

On the other hand, activity of $\mathrm{K}_{\text {ATP }}$ channels is also influenced by extracellular bioactive substances such as adenosine via G-protein-coupled receptors and their downstream signalings [5, 22]. Activation of Gs protein and $\mathrm{Gq} / 11$ protein results in opening and closing of $\mathrm{K}_{\mathrm{ATP}}$ channels, respectively. In line with this, $\mathrm{K}_{\mathrm{ATP}}$ channels might constitute a putative hormone and autacoidassociated regulatory pathway for esophageal motility.

For efficient peristalsis in the mammalian esophagus, contraction (excitation) and/or relaxation (inhibition) of striated and smooth muscles should be regulated appropriately. In the smooth muscle portion, motor activity is regulated by intrinsic excitatory and inhibitory motor neurons as the case in other parts of the gut $[9,13]$. On the other hand, it has been widely accepted that firing rate of vagal motor neurons controls contractile intensity of esophageal striated muscle $[9,13]$. In addition, a local neural reflex, which consists of capsaicin-sensitive sensory neurons and intrinsic nitrergic neurons, also might have important roles in inhibitory modulation of esophageal striated muscle $[8,16,26,28]$. The present study demonstrated that a control system of motor activity of esophageal striated muscle is included into muscular cells. This system can modulate contractile intensity of esophageal striated muscle by using gating mechanism of $\mathrm{K}_{\mathrm{ATP}}$ channels even if firing rate of vagal motor neurons is constant. Considering that closers of other types of potassium channels such as voltage-gated potassium channels and calcium-activated potassium channels also have been shown to have similar actions as $\mathrm{K}_{\mathrm{ATP}}$ channels blocker (unpublished observation), combination of gating of potassium channels with firing of vagal neurons and intrinsic neurons might contribute to efficient peristalsis in the esophageal striated muscle portion.

Achalasia, nutcracker esophagus and gastroesophageal reflux disease are known as esophageal motility disorders [27]. In addition, megaesophagus, which is characterized by decreased or absent esophageal motility that results in a diffuse dilation of the esophagus, is a common esophageal disease in dogs $[17,21,36]$. These disorders profoundly affect the quality of life of patients [12]. Since ion channels are often involved in dysfunction of gastrointestinal motility, several ion channels are potential targets for intervention in gastrointestinal motility disorders [6]. Therefore, $\mathrm{K}_{\text {ATP }}$ channels might be therapeutic targets for several esophageal motility disorders.

In conclusion, our study demonstrated that closing and opening of $\mathrm{K}_{\mathrm{ATP}}$ channels enhances and reduces contractility of esophageal striated muscle in rats, respectively. These findings indicate that $\mathrm{K}_{\mathrm{ATP}}$ channels contribute to motor regulation of striated muscle in the esophagus.

ACKNOWLEDGMENTS. This work was supported in part by the Koshiyama Research Grant (Gifu, Japan), Kieikai Research Foundation (Tokyo, Japan) and Grants-in-Aid for Scientific Research (KAKENHI) from the Ministry of Education, Culture, Sports, Science, and Technology of Japan [Research Project Numbers: 17K08122]. The authors are indebted to Prof. Yoshio Yamamoto (Iwate University, Japan), Dr. Ryosuke Morinaga (Iwate University, Japan), and Ms. Ayako Takahashi (Gifu University, Japan) for their technical supports.

\section{REFERENCES}

1. Argenzio, R. A. 1984. pp. 278-289. In: Duke’s Physiology of Domestic Animals, 10th ed. (Swenson, M. J. ed.), Cornell University Press, New York.

2. Ashcroft, F. M. and Gribble, F. M. 2000. New windows on the mechanism of action of $\mathrm{K}_{\mathrm{ATP}}$ channel openers. Trends Pharmacol. Sci. 21: 439-445. [Medline] [CrossRef]

3. Ashcroft, F. M., Harrison, D. E. and Ashcroft, S. J. 1984. Glucose induces closure of single potassium channels in isolated rat pancreatic beta-cells Nature 312: 446-448. [Medline] [CrossRef]

4. Babenko, A. P., Aguilar-Bryan, L. and Bryan, J. 1998. A view of sur/KIR6.X, KATP channels. Annu. Rev. Physiol. 60: 667-687. [Medline] [CrossRef]

5. Baukrowitz, T. and Fakler, B. 2000. $\mathrm{K}_{\mathrm{ATP}}$ channels gated by intracellular nucleotides and phospholipids. Eur. J. Biochem. 267: $5842-5848$. [Medline] [CrossRef]

6. Beyder, A. and Farrugia, G. 2012. Targeting ion channels for the treatment of gastrointestinal motility disorders. Therap. Adv. Gastroenterol. 5: 5-21. [Medline] [CrossRef]

7. Blondeau, N., Plamondon, H., Richelme, C., Heurteaux, C. and Lazdunski, M. 2000. $\mathrm{K}_{\text {ATP }}$ channel openers, adenosine agonists and epileptic preconditioning are stress signals inducing hippocampal neuroprotection. Neuroscience 100: 465-474. [Medline] [CrossRef]

8. Boudaka, A., Wörl, J., Shiina, T., Neuhuber, W. L., Kobayashi, H., Shimizu, Y. and Takewaki, T. 2007. Involvement of TRPV1-dependent and -independent components in the regulation of vagally induced contractions in the mouse esophagus. Eur. J. Pharmacol. 556: 157-165. [Medline] [CrossRef] 
9. Clouse, R. E. and Diamant, N. E. 2006. Motor Function of the esophagus. pp. 913-926. In: Physiology of the Gastrointestinal Tract, 4th ed. (Johnson, L. R. ed.), Elsevier Academic Press, Burlington.

10. Cook, D. L. and Hales, C. N. 1984. Intracellular ATP directly blocks K ${ }^{+}$channels in pancreatic B-cells. Nature 311: 271-273. [Medline] [CrossRef]

11. Edwards, G. and Weston, A. H. 1993. The pharmacology of ATP-sensitive potassium channels. Annu. Rev. Pharmacol. Toxicol. 33: $597-637$. [Medline] [CrossRef]

12. Furuzawa-Carballeda, J., Torres-Landa, S., Valdovinos, M. A., Coss-Adame, E., Martín Del Campo, L. A. and Torres-Villalobos, G. 2016. New insights into the pathophysiology of achalasia and implications for future treatment. World J. Gastroenterol. 22: 7892-7907. [Medline] [CrossRef]

13. Goyal, R. K. and Chaudhury, A. 2008. Physiology of normal esophageal motility. J. Clin. Gastroenterol. 42: 610-619. [Medline] [CrossRef]

14. Hatakeyama, N., Wang, Q., Goyal, R. K. and Akbarali, H. I. 1995. Muscarinic suppression of ATP-sensitive $\mathrm{K}^{+}$channel in rabbit esophageal smooth muscle. Am. J. Physiol. 268: C877-C885. [Medline] [CrossRef]

15. Hibino, H., Inanobe, A., Furutani, K., Murakami, S., Findlay, I. and Kurachi, Y. 2010. Inwardly rectifying potassium channels: their structure, function, and physiological roles. Physiol. Rev. 90: 291-366. [Medline] [CrossRef]

16. Izumi, N., Matsuyama, H., Ko, M., Shimizu, Y. and Takewaki, T. 2003. Role of intrinsic nitrergic neurones on vagally mediated striated muscle contractions in the hamster oesophagus. J. Physiol. 551: 287-294. [Medline] [CrossRef]

17. Kanemoto, Y., Fukushima, K., Kanemoto, H., Ohno, K. and Tsujimoto, H. 2017. Long-term management of a dog with idiopathic megaesophagus and recurrent aspiration pneumonia by use of an indwelling esophagostomy tube for suction of esophageal content and esophagogastric tube feeding. J. Vet. Med. Sci. 79: 188-191. [Medline] [CrossRef]

18. Kito, Y. and Suzuki, H. 2003. Modulation of slow waves by hyperpolarization with potassium channel openers in antral smooth muscle of the guinea-pig stomach. J. Physiol. 548: 175-189. [Medline] [CrossRef]

19. Koh, S. D., Bradley, K. K., Rae, M. G., Keef, K. D., Horowitz, B. and Sanders, K. M. 1998. Basal activation of ATP-sensitive potassium channels in murine colonic smooth muscle cell. Biophys. J. 75: 1793-1800. [Medline] [CrossRef]

20. Lee, J. Y., Ko, E. J., Ahn, K. D., Kim, S. and Rhee, P. L. 2015. The role of $\mathrm{K}^{+}$conductances in regulating membrane excitability in human gastric corpus smooth muscle. Am. J. Physiol. Gastrointest. Liver Physiol. 308: G625-G633. [Medline] [CrossRef]

21. Nakagawa, T., Doi, A., Ohno, K., Yokoyama, N. and Tsujimoto, H. 2019. Clinical features and prognosis of canine megaesophagus in Japan. J. Vet. Med. Sci. 81: 348-352. [Medline] [CrossRef]

22. Nelson, M. T. and Quayle, J. M. 1995. Physiological roles and properties of potassium channels in arterial smooth muscle. Am. J. Physiol. 268: C799-C822. [Medline] [CrossRef]

23. Neuhuber, W. L. and Wörl, J. 2016. Enteric co-innervation of striated muscle in the esophagus: still enigmatic? Histochem. Cell Biol. 146: 721-735. [Medline] [CrossRef]

24. Noma, A. 1983. ATP-regulated K+ channels in cardiac muscle. Nature 305: 147-148. [Medline] [CrossRef]

25. Pouokam, E., Bader, S., Brück, B., Schmidt, B. and Diener, M. 2013. ATP-sensitive K( $\left(^{+}\right)$channels in rat colonic epithelium. Pflugers Arch. 465: 865-877. [Medline] [CrossRef]

26. Shiina, T., Shima, T., Suzuki, Y., Wörl, J. and Shimizu, Y. 2012. Neural regulation of esophageal striated muscle in the house musk shrew (Suncus murinus). Auton. Neurosci. 168: 25-31. [Medline] [CrossRef]

27. Shiina, T., Shima, T., Wörl, J., Neuhuber, W. L. and Shimizu, Y. 2010. The neural regulation of the mammalian esophageal motility and its implication for esophageal diseases. Pathophysiology 17: 129-133. [Medline] [CrossRef]

28. Shiina, T., Shimizu, Y., Boudaka, A., Wörl, J. and Takewaki, T. 2006. Tachykinins are involved in local reflex modulation of vagally mediated striated muscle contractions in the rat esophagus via tachykinin NK1 receptors. Neuroscience 139: 495-503. [Medline] [CrossRef]

29. Shiina, T., Shimizu, Y., Izumi, N., Suzuki, Y., Asano, M., Atoji, Y., Nikami, H. and Takewaki, T. 2005. A comparative histological study on the distribution of striated and smooth muscles and glands in the esophagus of wild birds and mammals. J. Vet. Med. Sci. 67: 115-117. [Medline] [CrossRef]

30. Shimbo, T., Adachi, T., Fujisawa, S., Hongoh, M., Ohba, T. and Ono, K. 2016. In vitro effect of nicorandil on the carbachol-induced contraction of the lower esophageal sphincter of the rat. J. Pharmacol. Sci. 131: 267-274. [Medline] [CrossRef]

31. Spruce, A. E., Standen, N. B. and Stanfield, P. R. 1985. Voltage-dependent ATP-sensitive potassium channels of skeletal muscle membrane. Nature 316: 736-738. [Medline] [CrossRef]

32. Standen, N. B., Quayle, J. M., Davies, N. W., Brayden, J. E., Huang, Y. and Nelson, M. T. 1989. Hyperpolarizing vasodilators activate ATP-sensitive $\mathrm{K}^{+}$channels in arterial smooth muscle. Science 245: 177-180. [Medline] [CrossRef]

33. Sun, Y. D. and Benishin, C. G. 1994. K+ channel openers relax longitudinal muscle of guinea pig ileum. Eur. J. Pharmacol. 271: $453-459$. [Medline] [CrossRef]

34. Tricarico, D., Selvaggi, M., Passantino, G., De Palo, P., Dario, C., Centoducati, P., Tateo, A., Curci, A., Maqoud, F., Mele, A., Camerino, G. M., Liantonio, A., Imbrici, P. and Zizzo, N. 2016. ATP Sensitive Potassium Channels in the Skeletal Muscle Function: Involvement of the KCNJ11(Kir6.2) Gene in the Determination of Mechanical Warner Bratzer Shear Force. Front. Physiol. 7: 167. [Medline] [CrossRef]

35. Vogalis, F. 2000. Potassium channels in gastrointestinal smooth muscle. J. Auton. Pharmacol. 20: 207-219. [Medline] [CrossRef]

36. Washabau, R. J. 2003. Gastrointestinal motility disorders and gastrointestinal prokinetic therapy. Vet. Clin. North Am. Small Anim. Pract. 33: 1007-1028, vi. [Medline] [CrossRef]

37. Wörl, J. and Neuhuber, W. L. 2005. Enteric co-innervation of motor endplates in the esophagus: state of the art ten years after. Histochem. Cell Biol. 123: 117-130. [Medline] [CrossRef]

38. Yeung, C. K., McCurrie, J. R. and Wood, D. 2002. Characterisation of the effects of potassium channel modulating agents on mouse intestinal smooth muscle. J. Pharm. Pharmacol. 54: 425-433. [Medline] [CrossRef] 